\title{
Research and analysis of new paste filling material based on red mud iron tailings
}

\author{
Lihua Wang ${ }^{1}$, Jie Zhang ${ }^{2}$ and Gaochao Sun ${ }^{3}$ \\ 1,2,3 College of Civil Engineering and Architecture, Shandong University of Science and Technology, 266590, Qingdao, Shandong.
}

\begin{abstract}
In order to reduce the amount of high energy consumption materials such as cement in filling, save resources, and fully recycle industrial waste. In this paper, Changxing coal mine as the research background, through data analysis, and through the test configuration based on red mud iron tailings, mixed with desulfurization gypsum, lime, cement, activator of new cementitious materials. And through the test analysis, the best proportion of coagulant admixture is determined as follows: red mud iron tailings dosage 6 , cement sand ratio 1:3, mass concentration $68 \%$.
\end{abstract}

\section{INTRODUCTION}

In China, mining industry is an important foundation of economy and energy, which provides more than $92 \%$ of national energy, more than $75 \%$ of resources are provided in industrial raw materials, and more than $68 \%$ in agricultural production materials ${ }^{[1-2]}$. The progress of social production development is inseparable from the development and utilization of mineral resources. Therefore, in the economic development activities of human society, the mining of mineral resources is very important.

However, there are two sides to everything, which will bring various geological disasters to the mining of mine resources, such as well flooding caused by the expansion of water fracture zone, subsidence of mining area, and geological instability of mining field and roadway in mining area, making the site face greater engineering geological disasters and other problems ${ }^{[3-4]}$. Moreover, the private mining enterprises are also increasing with the development of economy. In addition, the standardization and scientificity of management are relatively lagging behind. Therefore, in the mining process, due to the nonstandard and lack of scientific operation, the geological conditions of various mine geotechnical engineering are caused Disasters occur frequently in various regions, giving the society development alarm ${ }^{[4-}$
$5]$.

In this paper, Changxing coal mine as the research background, through the experiment configuration based on red mud iron tailings, mixed with desulfurization gypsum, lime, cement, activator new cementitious materials. This paper studies and analyzes the interaction mechanism of coagulant admixture for iron tailings from red mud separation, and determines the optimal proportion of coagulant admixture through experimental analysis. Then, the whole tailings are used as aggregate and new cementitious materials are added to prepare filling materials. The influence of cement sand ratio and mass concentration on the bleeding rate, fluidity and compressive strength of filling materials is analyzed through experimental study. According to the relevant engineering requirements and the analysis of relevant experimental data, the final configuration of paste filling slurry is determined.

\section{PROJECT OVERVIEW}

Changxing coal mine is located in Yulin City, north of the ancient Great Wall, with an area of $13.03 \mathrm{~km} 2$. The mine is located in the south of maowu desert. The local landform is mainly semi fixed desert beach and sand dune. The desert coverage rate of the whole area is above $70 \%$.

The physical and mechanical parameters of coal mine stratum are shown in table 2.2.

Table 1 Rock mass parameters

\begin{tabular}{|c|c|c|c|c|c|c|c|c|}
\hline $\begin{array}{c}\text { Serial } \\
\text { number }\end{array}$ & Name & $\begin{array}{c}\text { Thickness } \\
/ \mathrm{m}\end{array}$ & $\begin{array}{l}\text { Bulk density / } \\
\left(\mathrm{kg} / \mathrm{m}^{3}\right)\end{array}$ & $\mathrm{E} / \mathrm{Mpa}$ & $\begin{array}{l}\text { Poisson's } \\
\text { ratio }\end{array}$ & $\begin{array}{c}\text { Tensile } \\
\text { strength } \\
/ M p a\end{array}$ & $\begin{array}{l}\text { Adhesion } \\
\qquad / M p a\end{array}$ & $\begin{array}{l}\text { Internal } \\
\text { friction } \\
\text { angle } /^{\circ}\end{array}$ \\
\hline 8 & Sand layer & 82.3 & 1910 & 20 & 0.40 & 0.23 & 0.049 & 27 \\
\hline 7 & Siltstone & 62.1 & 2270 & 421 & 0.19 & 3.5 & 5.34 & 41.1 \\
\hline
\end{tabular}

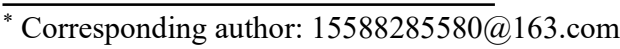




\begin{tabular}{ccccccccc}
\hline 6 & $\begin{array}{c}\text { Medium- } \\
\text { grained } \\
\text { sandstone }\end{array}$ & 7.3 & 2310 & 674 & 0.35 & 0.7 & 2.08 & 39.5 \\
\hline 5 & $\begin{array}{c}\text { Medium- } \\
\text { grained } \\
\text { sandstone }\end{array}$ & 30.2 & 2420 & 4931 & 0.18 & 3.3 & 5.48 & 39.1 \\
\hline 4 & $\begin{array}{c}\text { Fine-grained } \\
\text { sandstone }\end{array}$ & 13.1 & 2430 & 4928 & 0.17 & 2.9 & 4.89 & 39.4 \\
\hline 3 & $\begin{array}{c}\text { Argillaceous } \\
\text { sandstone }\end{array}$ & 6.3 & 2450 & 2518 & 0.17 & 1.4 & 2.5 & 38.2 \\
\hline 2 & Coal & 3.5 & 1300 & 2037 & 0.29 & 1.6 & 2.7 & 37.2 \\
\hline 1 & Siltstone & 17.9 & 2390 & 4970 & 0.13 & 2.5 & 5.47 & 40.1 \\
\hline
\end{tabular}

\section{EXPERIMENTS}

At present, in paste filling, the state has not yet issued relevant experimental procedures or standards. This experiment mainly refers to the technical standards of concrete, mainly including: Standard for performance test method of ordinary concrete mixture (GB / t50080-2002). Through literature review, analysis and summary ${ }^{[5-7]}$, it is determined that the mass percentage of lime is $2.0 \%, 3.0 \%$ and $4.0 \%$, and that of desulfurization gypsum (mainly $\mathrm{CaSO} 4 \cdot 2 \mathrm{H} 2 \mathrm{O}$ ) is $8.0 \%, 9.0 \%$ and $10.0 \%$. Under the condition of determining the optimal ratio, the optimal ratio of $\mathrm{Na} 2 \mathrm{SiO} 3, \mathrm{Na} 2 \mathrm{SO} 4$ and $\mathrm{CaCl} 2$ is $1.0 \%, 1.5 \%$ and $1.5 \%$ respectively.

Cementitious materials were used as gelling agent and tailings as aggregate. Based on the analysis of relevant literature, it is determined that the mortar ratio of the experimental group is $1: 1,1: 2,1: 3,1: 4$, and the mass percentage is $66 \%, 68 \%, 70 \%$ and $72 \%$. Through the analysis of bleeding rate, fluidity and compressive strength of test block in $3 \mathrm{D}, 7 \mathrm{~d}$ and $28 \mathrm{~d}$, the best configuration ratio is selected according to the case

\subsection{Mobility analysis}

Through the range calculation and analysis of experimental data, the arrangement is shown in the figure below.

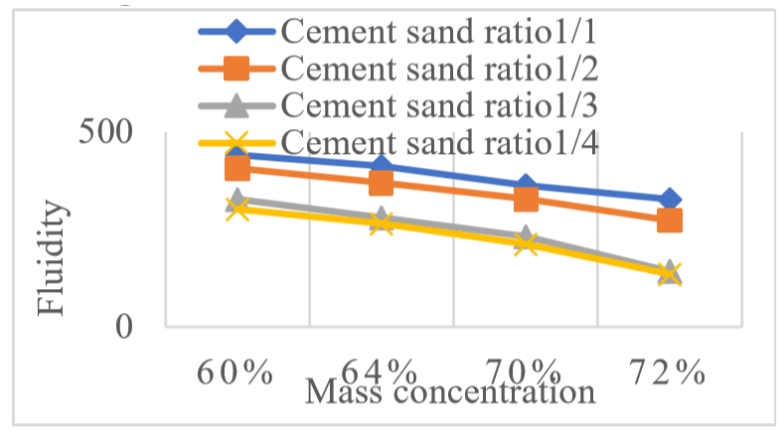

Fig.1 Mobility curve

From the above data analysis, it can be seen that with the decrease of the dosage of gel material, the fluidity of slurry decreases, and with the increase of mass concentration, the fluidity of slurry decreases. Because the gel content is not mixed in percentage, the curve is nonlinear. The mass concentration is tested according to the percentage, so the curve is approximately linear. With the increase of mass concentration, the fluidity of slurry decreases. Because the gel content is not mixed in percentage, the curve is nonlinear. The mass concentration is tested according to the percentage, so the curve is approximately linear. Through the range value $\mathrm{R}$ mortar ratio $>\mathrm{R}$ mass concentration, it is concluded that the rubber sand ratio has a greater influence on the bleeding rate of slurry in this test, and the reason is partly related to the material ratio. Through the range value $\mathrm{R}$ mortar ratio $>\mathrm{R}$ mass concentration, it is concluded that the ratio of binder to sand has greater influence on the fluidity of slurry. According to the relevant data, the mass concentration has a greater influence on the bleeding rate. The reason is partly related to the way of configuration, that is, the percentage of gel material conversion is $50 \%, 33.3 \%, 25 \%$ and $20 \%$, showing an asymmetric proportion.

\subsection{Bleeding rate analysis}

Through the range calculation and analysis of the experimental data, the following figure is shown

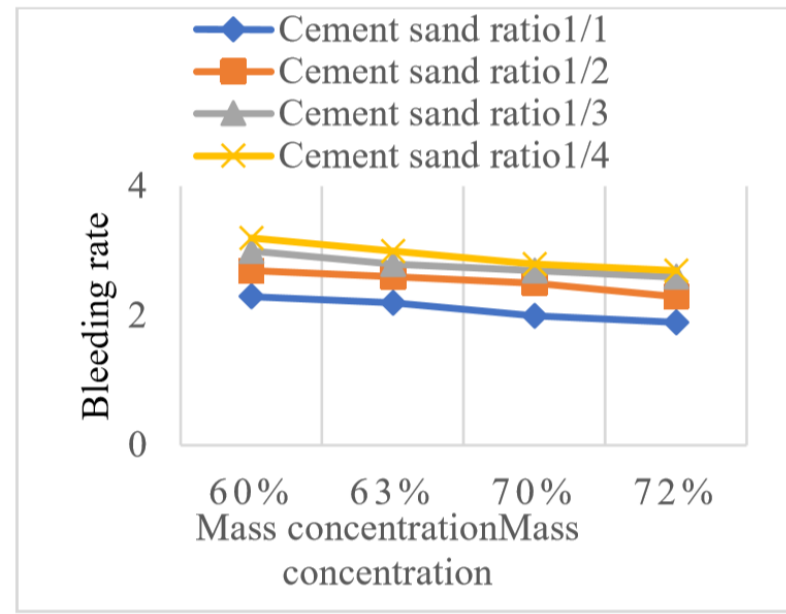

Fig.2 Change curve of bleeding rate

From the above data analysis, it can be seen that with the increase of the gel material content, the bleeding of the slurry

The rate increases, and as the mass concentration increases, the fluidity of the slurry decreases. Because the 
gel content is not mixed in percentage, the curve is nonlinear; the mass concentration is tested in percentage, so the curve is approximately linear. According to the range value $R$ mortar ratio $>R$ mass concentration, it is concluded that the mortar-sand ratio in this experiment has a greater influence on the bleeding rate of the slurry, and the reason is partly related to the material ratio through analysis.

\subsection{Compressive strength analysis}

Through the range calculation and analysis of the experimental data, the following figure is shown

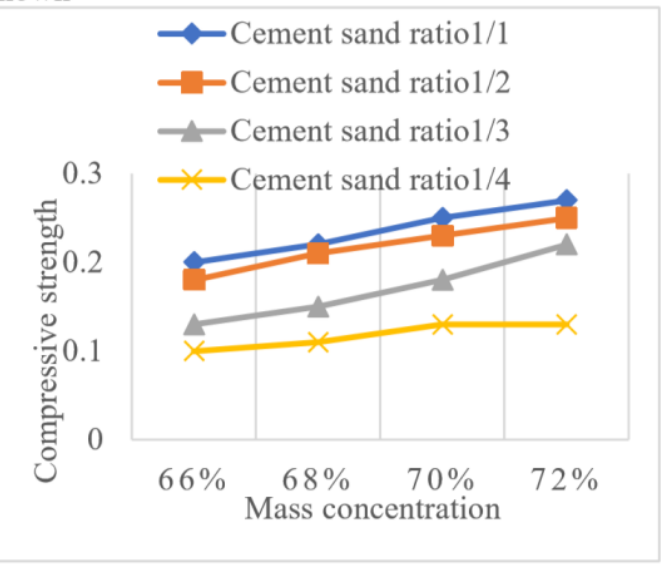

Fig. 3 8h strength curve

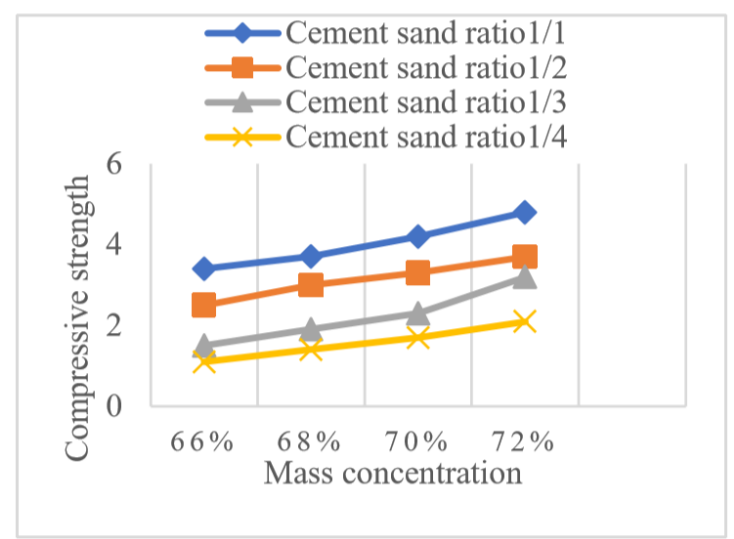

Fig.4 3d strength curve

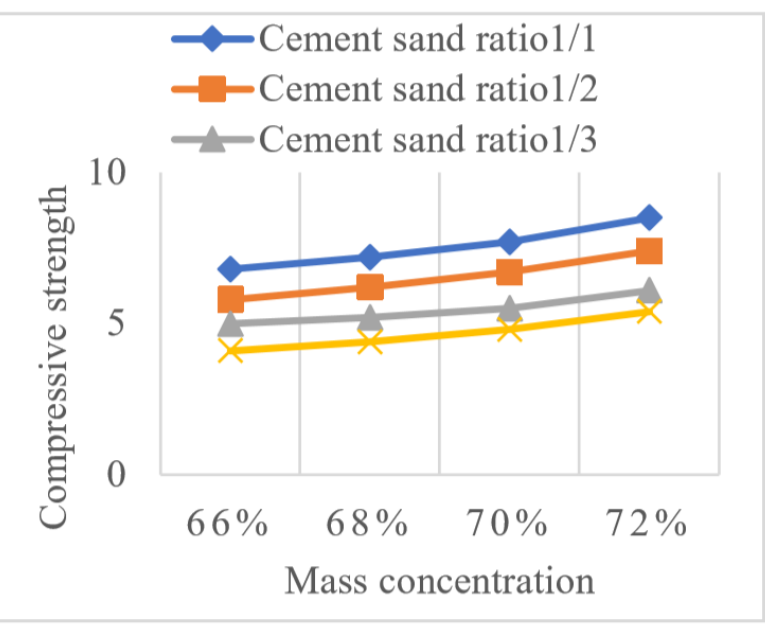

Fig. 5 7d strength curve

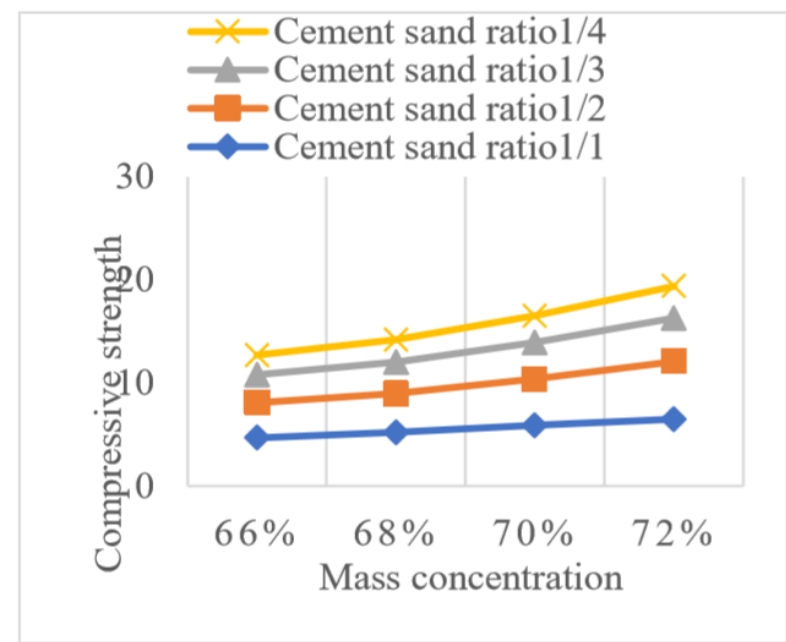

Fig.6 28d strength curve

Through the above data analysis, it can be seen that when the mass concentration is constant, the strength of the test block increases with the increase of the gel material content, and when the mortar ratio is constant, the strength of the test block increases with the increase of the mass concentration. Through the range value $\mathrm{R}$ mortarsand ratio $>R$ mass concentration, it can be seen that the mortar-sand ratio in this test has a greater influence on the strength of the test block. Pass and related

The reason for the comparative analysis of the experimental data of the data is not only related to the mixing amount, but also to the configuration of the mortar, that is, the configuration conversion percentage of the gel material is $50 \%, 33.3 \%, 25 \%$, and $20 \%$ in an asymmetric ratio; The concentration has to be configured as $66 \%, 68 \%$, $70 \%, 72 \%$, which is relatively uniform.

\section{CONCLUSIONS}

According to the experimental data, when the mortar ratio is $1: 3$ and the mass concentration is $68 \%$, the fluidity of the filling slurry is $280 \mathrm{~mm}$, the bleeding rate is $2.8 \%$, and the uniaxial compressive strength of $8 \mathrm{~h}$ is $0.15 \mathrm{MPa}, 3 \mathrm{~d}$ The uniaxial compressive strength is $1.9 \mathrm{MPa}$, the uniaxial compressive strength of $7 \mathrm{~d}$ is $3.0 \mathrm{MPa}$, and the uniaxial compressive strength of $28 \mathrm{~d}$ is $5.2 \mathrm{MPa}$, which meets the relevant engineering requirements. Through comprehensive consideration, the performance index of the filler slurry is finally determined: mortar ratio $1: 3$. The mass concentration is $68 \%$.

\section{References}

1. Wang Xiuqiang. "Twelfth Five-Year Plan" and S tructural Adjustment of Coal Industry. 21st Cent ury Business Herald, 2012(2)

2. He Youguo. 2016 China Coal Development Rep ort [M]. Beijing: Coal Industry Press, 2016: 2-8.

3. $\mathrm{Xu}$ Jialin, Xuan Dayang, Zhu Weibing. Current status and prospects of backfill mining technolo gy[J]. Mining Technology. 2011(03): 24-30.

4. Xia Changnian, Sun Xuesen. Application status and development trend of filling mining method and filling technology $[\mathrm{J}]$. China Mining Engin 
eering, 2014, 43(1): 61-64.

5. Yu Yue,Cheng Kun,Pang Bo.Rheological properti es of high concentration cemented backfilling sl urry[J].Electronic Journal of Geotechnical Engin eering,2016 (21.7):1611-1619.

6. Yang Baogui,Du Xueling,Dang Peng.The cement ed filling technology using special filling roadw ay in gob[J].Electronic Journal of Geotechnical Engineering,2015 (20.8):2087-2094.

7. Ayhan Kesimal,Erol Yilmaz,Bayram Ercikdi.Eff ect of properties of tailings and binder on $t$ he short and long term strength and stability of cemented paste backfill[J].Engineering Geol og y,2011(123):288-295. 